\title{
Optimization of soft armor: the response of single-ply para-aramid and ultra-high molecular weight polyethylene fabrics under ballistic impact
}

Ralph, C., Baker, L., Archer, E., \& Mcllhagger, AT. (2020). Optimization of soft armor: the response of single-ply para-aramid and ultra-high molecular weight polyethylene fabrics under ballistic impact. Textile Research Journal, 90 (15-16), 1713-1729. https://doi.org/10.1177/0040517519900384

Link to publication record in Ulster University Research Portal

\section{Published in:}

Textile Research Journal

Publication Status:

Published (in print/issue): 01/08/2020

DOI:

10.1177/0040517519900384

\section{Document Version}

Author Accepted version

\section{General rights}

Copyright for the publications made accessible via Ulster University's Research Portal is retained by the author(s) and / or other copyright owners and it is a condition of accessing these publications that users recognise and abide by the legal requirements associated with these rights.

\section{Take down policy}

The Research Portal is Ulster University's institutional repository that provides access to Ulster's research outputs. Every effort has been made to ensure that content in the Research Portal does not infringe any person's rights, or applicable UK laws. If you discover content in the Research Portal that you believe breaches copyright or violates any law, please contact pure-support@ulster.ac.uk. 


\section{Optimisation of soft armour: The response of single-ply para-aramid and UHWMPE fabrics under ballistic impact}

\section{Abstract}

Typical soft armour systems are constructed of multiple layers of a single fabric type. This empirical research sought to begin optimisation of these systems through hybridisation, sequencing dissimilar armour fabrics to maximise their ballistic protective performance, by first investigating single plies with a spectrum of properties to determine their behaviour and response to impact. Eight individual plain weave fabrics with varying yarns and thread counts were manufactured from para-aramid and UHMWPE yarns and physical and ballistic characterisations were conducted. The ballistic impact tests established the specific energy absorption (SEA) of each fabric across a range of impact velocities (340 m-s-1- $620 \mathrm{~m} \cdot \mathrm{s}-1)$ and the transverse displacement wave velocity across the rear of the fabric was found using digital image correlation. Low cover factor $\left(\mathrm{C}_{\mathrm{fab}}\right)$ fabrics $(0.74-0.84)$ consistently showed faster transverse wave speed than the high $\mathrm{C}_{\mathrm{fab}}$ fabrics $(0.84-0.96)$ for any given yarn type. The relative SEA of the fabrics varied dependent on both impact velocity and number of plies impacted. It was found that lower $\mathrm{C}_{\mathrm{fab}}$ fabrics had the highest SEA, critical velocity and transverse wave velocity. UHMWPE fabrics were not considered suitable for a woven hybrid system as they had a significantly lower SEA compared to all the para-aramid fabrics. Results indicate that a hybrid system, when considered as theoretical spaced system, would benefit from higher $\mathrm{C}_{\mathrm{fab}}$ fabrics as rearward layers. However, transverse wave results suggest the lower response of these fabrics may inhibit lower $\mathrm{C}_{\text {fab }}$ fabrics at the front of a combined hybridised system.

\section{Keywords:}

Soft armour; Ballistic impact; Energy absorption; para-aramid; UHMWPE 


\section{Introduction}

Body armour is a broad term used to describe a range of protective equipment from sportswear or personal protection for police forces or armed forces. Military personal protection typically consists of hard and soft armour elements where the hard armour is present in the form of ballistic plate inserts which cover the critical bodily organs and provide protection against high velocity rifle rounds. However, the soft armour is also a critical component. Soft armour is used in military personal protection to protect against fragments from explosive devices such as hand grenades or mortars and generally sits behind the hard armour and extends around the body providing greater anatomical coverage. The necessity of such armour systems can be seen from casualty analysis data from historic and recent conflicts. Surveys of the Korean war identified that soft armour vests defeated the majority of low velocity fragments with a $70 \%$ reduction in torso wounds when the armour was worn [1]. Recent conflict in Afghanistan highlighted the efficiency of soft armour where data from the UK/US Joint Theatre Registry 2011 Report shows that, of injuries sustained as the result of an explosive device, 7 out of 10 were to the relatively unprotected extremities and only 1 in 10 were to the protected torso [2].

In 1915, documented research by the British Bureau of Munitions identified silk as the best performing fibre of its time [3]. However, the ban on Japanese silk exports to America during WWII instigated the development of alternative materials into soft armour. By the end of the war, the M1951, a service issue nylon system was introduced marking the beginning of synthetic fibre body armours [1]. Nylon remained the prominent constituent fibre in soft armour fabric until the development of Kevlar® 29, a para-aramid yarn commercialised by Dupont in 1972. High modulus and high tenacity being advantageous properties of armour fibres, Kevlar® represented a step change in performance showing a strength 2.5 times that of nylon and an elastic modulus an order of magnitude greater [4-6]. In 1990, Ultra-High Molecular Weight Polyethylene (UHMWPE) was subsequently introduced to market by DSM under the brand name Dyneema ${ }^{\circledR}$, meaning strong fibre in Greek. Dyneema® has certain 
strength and modulus advantages over Kevlar® but the unique properties of each mean that they both feature in today's soft armour market. Other companies that have since introduced similar yarns include Teijin who produce a para-aramid branded as Twaron ${ }^{\circledR}$ and Honeywell who produce an UHMWPE under the name Spectra®.

The hierarchy of military survivability places 'not being hit' above 'being adequately protected', as such, the balance between protection and agility has long been an issue in the development of personal armour systems. Its cumbersome and weighty design lead to the demise of the body armour in the middle ages and its reluctant use in both world wars is testimony that the design needs to meet the needs of the user as well as the prospective threat $[7,8]$. It is, however, the threat that defines the type of materials that are incorporated into soft armour systems and therefore, their net weight. The current UK military service issue armour system includes soft armour protection for the torso, neck, shoulder and groin to combat the spectrum of threats in operational theatres [9]. Consequently, modern personal armour systems can weigh up to $16 \mathrm{~kg}$, including hard armour, and may lack flexibility, inhibiting the wearer from performing their function [10]. In addition to this weight, the user can be subjected to a large thermal burden if they have to wear the armour for long periods or in hot climates. Human factors studies have shown that this burden can affect a soldiers physical and cognitive function, therefore increasing their vulnerability $[11,12]$. Both the UK MOD and US DoD have active burden reduction programmes which encompass armour materials creating pressure on industry to improve existing body armour systems $[13,14]$. In terms of personal protection, burden reduction is commonly associated with a reduced mass system, although increased ventilation, flexibility and fit have also been considered [9]. A reduced mass system can either be gained from a reduction in threat or from improvements in material performance. To this end, research has not only focussed on developing better, higher performing fibres for use in body armour, but has also looked at how these fibres can be formed into fabrics to improve qualities and performance of the end product. 
Soft armour is produced as multiple layered system of approximately 20-40 ballistic protective plies [15]. These plies may take the form of uni-directional (UD) laminates or woven fabrics and in a few cases, felts. However, this research only focusses on woven fabrics. A soft armour system works by dissipating the strain induced by an impacting projectile through the thickness of the system and across each layer and the failure mode of each ply changes from front to rear [16]. In the front layers of the system the strain in the fabric is often localised and yarns are sheared by the impacting projectile creating a material plugging failure. Rearward layers tend to undergo a tensile failure having been cushioned from the initial projectile impact. A tensile failure is marked by the propagation of strain along the impacted yarns and a transverse fabric deflection [17]. Recently, hybrid systems are appearing in the market where the composition may contain two or more different ply types $[18,19]$. Hybridising the system is thought to take advantage of the changing failure mode through the thickness of the system and the layer to layer interactions, although relatively few studies have been conducted in this field.

This research sought to investigate the potential of hybridisation through manipulation of the weave parameters and yarn type of each constituent ply. It is concerned with improving the ballistic protective performance of a multiple ply soft armour system by selectively stacking dissimilar layers within the system. Literature indicates that the holistic ballistic performance of armour systems can be influenced by the constituent fabric properties but few studies capture trends in the fundamental impact response with these various properties $[18,20,21]$ with most recent studies focusing on specific fabrics or modelling of them [22-24].

\section{Materials and methods}

Two types of yarn used during this study were Teijin Twaron ${ }^{\circledR}$ para-aramid and Dyneema ${ }^{\circledR}$ ultra-high-molecular-weight polyethylene (UHMWPE). A summary of the yarns used with their test references can be found in Table 1. Test reference is an abbreviation of yarn type, yarn linear density and thread count. All fabrics from the detailed yarns were manufactured 
as single layer plain weaves using a Bonas Jacquard loom providing fabrics of $35 \mathrm{~cm}$ width.

For SK/1760 yarns $8 \times 8$ was the maximum achievable thread count due to difficulties and quality issue evident above this value. Similarly, for CT/840 yarns the maximum thread count was $10 \times 10$.

Table 1: Specifications of yarns and woven fabric samples

\begin{tabular}{lllc}
\hline Yarn Type & Reference & Yarn & $\begin{array}{c}\text { Thread count Warp } x \\
\text { Weft / yarns·cm-1 }\end{array}$ \\
\hline \multirow{2}{*}{ Dyneema ${ }^{\circledR}$ UHMWPE } & SK/1760/6 & SK76 1760 dTex & $6 \times 6$ \\
& SK/1760/7 & SK76 1760 dTex & $7 \times 7$ \\
& SK/1760/8 & SK76 1760 dTex & $8 \times 8$ \\
\hline & CT/840/8 & CT2000 840 dTex & $8 \times 8$ \\
& CT/840/10 & CT2000 840 dTex & $10 \times 10$ \\
Twaron $^{\circledR}$ para-aramid & CT/550/10 & CT2040 550 dTex & $10 \times 10$ \\
& CT/550/12 & CT2040 550 dTex & $12 \times 12$ \\
& CT/550/14 & CT2040 550 dTex & $14 \times 14$ \\
\hline
\end{tabular}

Cover factor $\left(\mathrm{C}_{\mathrm{fab}}\right)$ for the warp $(\mathrm{wp})$ and weft $(\mathrm{wf})$ yarns were initially calculated from the ratio between the physical yarn diameter $d$ and the pitch $p_{w, f}$, Eq 1 . The net or fabric cover factor was then calculated by combining the individual warp and weft cover factor values removing the area where the yarns overlap, Eq. 2. The cover factor was calculated using the data provided in the material specification and by direct measurement of the woven fabric.

$C_{w p, w f}=d / p_{w p, w f}$

$C_{f a b}=C_{w p}+C_{w f}-C_{w p} C_{w f}$

Two types of ballistic test were used to investigate the impact response of the fabric. A residual velocity test was used to capture the energy absorption capability of each fabric sample. The second ballistic test captured the back face displacement of the fabric samples under impact with two offset high speed cameras (Photron FASTCAM SA5, 50mm Nikon lens and Bowen's flash lamp). Ballistic testing was conducted on a helium gas gun with a pressure of up to 300 bar. A schematic of the test set-up used can been seen in Fig.1. A stainless steel $0.7 \mathrm{~g}$ sphere projectile was used in place of a $1.1 \mathrm{~g}$ chisel nosed Fragment 
Simulating Projectile (FSP). The lower mass of the sphere enabled greater differentiation between pre-impact and post impact velocities. Unlike a FSP, the sphere projectile has a consistent strike face regardless of impact angle thus allowing consistent and accurate comparisons between test fabrics. The projectile was fired from a $7.62 \mathrm{~mm}$ calibre, 1 in 12 twist rifled barrel using a bespoke nylon sabot used to help achieve maximum velocity possible with given firing system. Projectile impact properties ranged from $320 \mathrm{~m} \cdot \mathrm{s}^{-1}$ to $640 \mathrm{~m} \cdot \mathrm{s}^{-1}$ and were bracketed into eight $40 \mathrm{~m} \cdot \mathrm{s}^{-1}$ intervals with five tests performed at each interval for all test fabrics. Test fabrics were cut to $150 \times 150 \mathrm{~mm}$ then mounted and clamped in a bespoke aluminium frame. The frame was designed to clamp the four corners leaving the edges free.

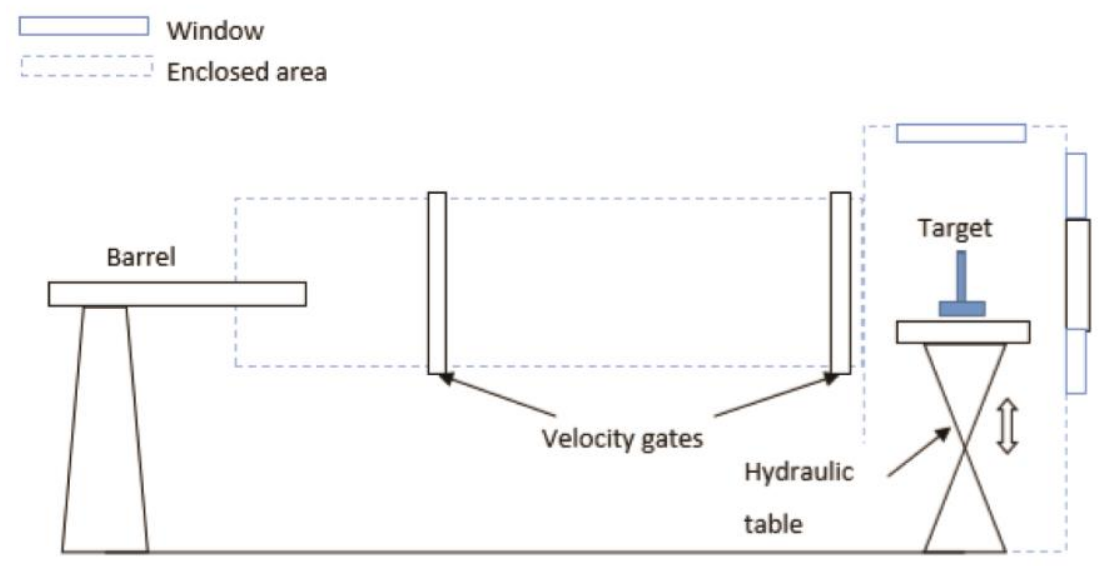

(a) Gas gun firing set-up

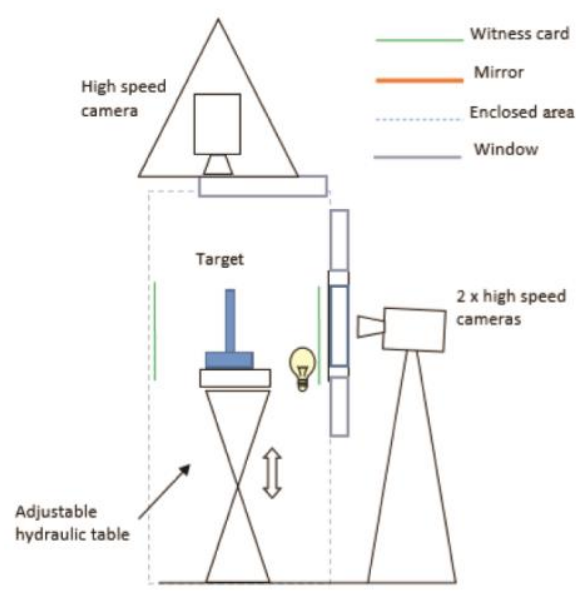

(b) Side view of camera and target set-up

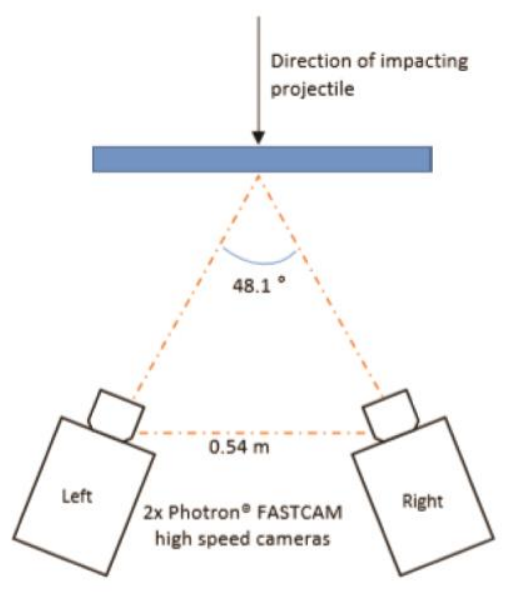

(c) Top view of camera and target set-up

Fig. 1. - Schematic of test set-up used for ballistic testing of fabrics for energy absorption, transverse and strain wave propagation. 
Energy absorbed by the fabric was calculated using Eq. 3 where $m$ is the projectile mass and $V_{i}$ and $V_{r}$ are the impact and residual velocities. The projectile remains intact and nondeformed during impact so it can be assumed that there is no mass lost and all energy lost is transferred or absorbed by the target.

$E_{a b s}=\frac{1}{2} m\left(V_{i}^{2}-V_{r}^{2}\right)$

The two high speed cameras were set-up to capture the in-plane and out-of-plane response of the target fabrics. Digital image correlation (DIC) was then used to analyse the relative velocities of the transverse waves induced by impact. Target fabrics were cut to $300 \mathrm{x}$ $300 \mathrm{~mm}$ and stencilled with a unique speckle pattern using a foam roller and Marsh stencil ink. Fabrics were then clamped on all four edges causing the strike area to be reduced to $250 \times 250 \mathrm{~mm}$.

Single yarn ballistic impact testing was performed using a similar method as that for fabrics except with a different compressed air gas gun, allowing the specimen to be positioned vertically and closer to the barrel thus improving accuracy and frequency of impact. Target yarn of $\sim 1.8 \mathrm{~m}$ was wrapped around a dowel at one end and tied off ensuring not to twist the yarn. Ink marks were made at $10 \mathrm{~mm}$ intervals along the first $1.2 \mathrm{~m}$ to enable tracking of the strain wave in video analysis. The dowel was then mounted to the roof of the firing chamber with the bottom end being wrapped around a second dowel so the final gauge length was $1.64 \mathrm{~m} .10$ twists per metre were added to ensure the yarn was an aligned and compact target. A mass of $150 \mathrm{~g}$ is then suspended from the bottom dowel to minimise movement caused by gases escaping from the barrel prior to impact. The projectile was fired without sabot from a smooth bore $5.56 \mathrm{~mm}$ barrel for the two lower impact velocities $(220 \mathrm{~m} \cdot \mathrm{s}-1$ and $290 \mathrm{~m} \cdot \mathrm{s}-1)$ and a further impact velocity of $430 \mathrm{~m} \cdot \mathrm{s}-1$ was achieved using a $7.62 \mathrm{~mm}$ sabot and rifled barrel using an air cylinder. The preferential impact velocity for these tests would be $340 \mathrm{~m} \cdot \mathrm{s}-1$ corresponding with the fabric tests. However, this velocity was not within the limits of either system and as such the wave velocities of $340 \mathrm{~m} \cdot \mathrm{s}-1$ were interpolated from the results. 
Crimp was measured following the procedure outlined in BS ISO 7211-3. A section of fabric is measured and the yarns are harvested and clamped at either end. Force is applied to one end of the specimen yarn and the extension is measured. Crimp is the ratio of the extension to original length and is usually expressed as a percentage.

\section{Results and Discussion}

3.1 Single-ply fabric energy absorption

The mean specific energy absorbed (SEA) for each fabric type across all velocity brackets is shown in Fig. 2.

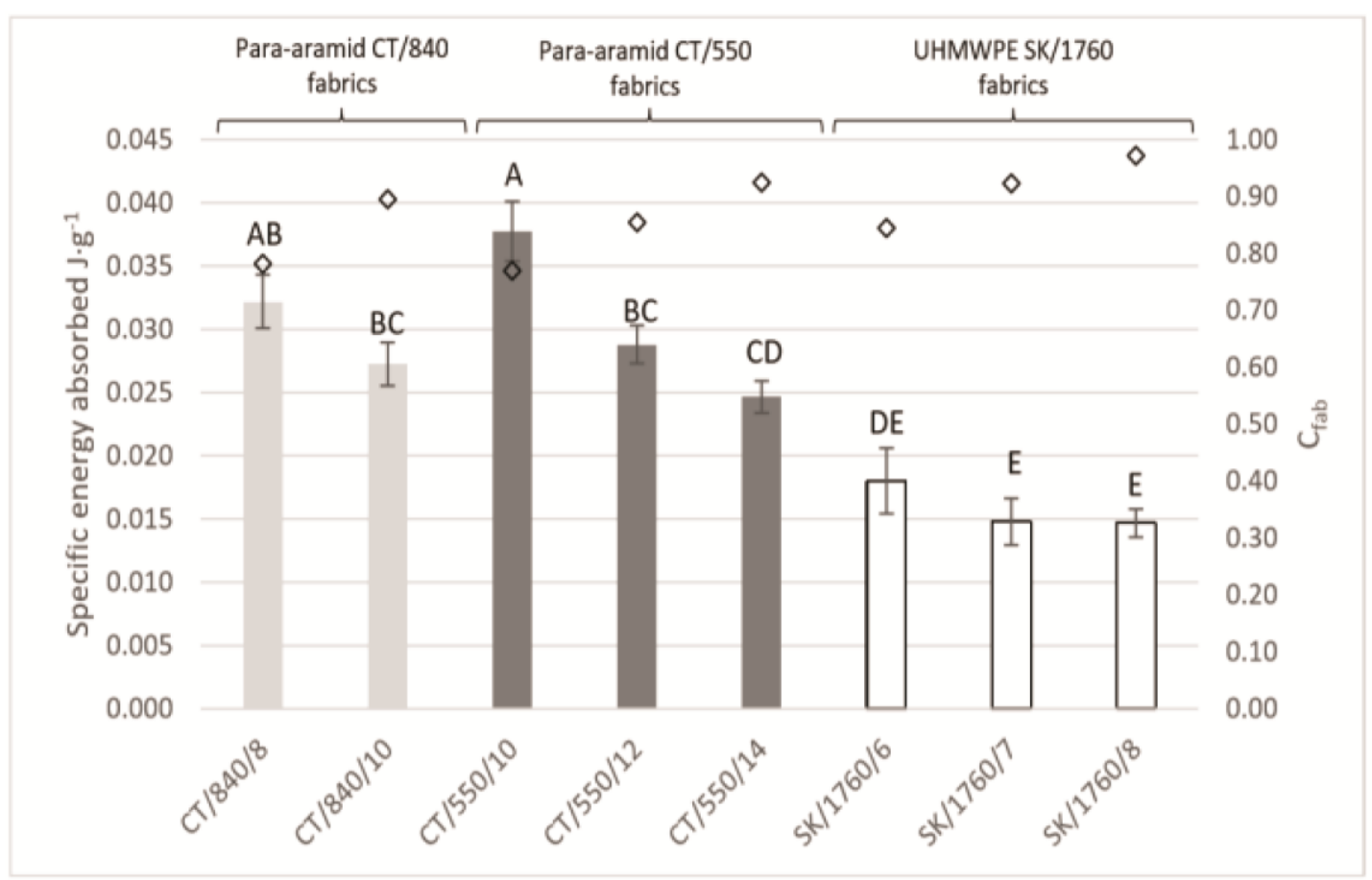

Fig. 2. - Mean SEA for all fabrics across all velocity brackets. Means displayed with standard error. Letters indicate statistically different results (Tukey's HSD $p<0.05$ ).

One factor ANOVA conducted identifies statistically significant differences in the SEA across all fabrics $(F 7,56=20.55, p=2.6 \times 10-5)$. This was followed by Tukey's Honest Significant Difference (HSD) test to make specific pairwise comparisons (Tukey HSD $\alpha<0.05$ ) with statistically significant different results being indicated by letters according to Tukey (Fig. 2). On average, the para-aramid fabrics had an $81 \%$ greater SEA than the UHMWPE fabrics in this study. The para-aramid with the highest SEA (CT/550/12) having over twice the energy 
absorption capacity of the highest performing UHMWPE fabric (SK/1760/8). Within each fabric set, the individual fabrics generally appeared to show a reduced SEA with increasing $\mathrm{C}_{\mathrm{fab}}$, although, the only statistically significant difference was noted between the highest $\mathrm{C}_{\mathrm{fab}}$ fabric and two lower $\mathrm{C}_{\mathrm{fab}}$ fabrics in the $\mathrm{CT} / 550 / \mathrm{XX}$ fabric set.

The SEA profiles at each velocity for para-aramid and UHMWPE fabrics are shown in Fig. 3 and Fig. 4 respectively. Both para-aramid and UHMWPE fabrics indicate a reduction in energy absorption with increasing impact velocity. The data suggests that the reduction in energy absorbed is disjointed and not a gradual decline across the velocity range tested.

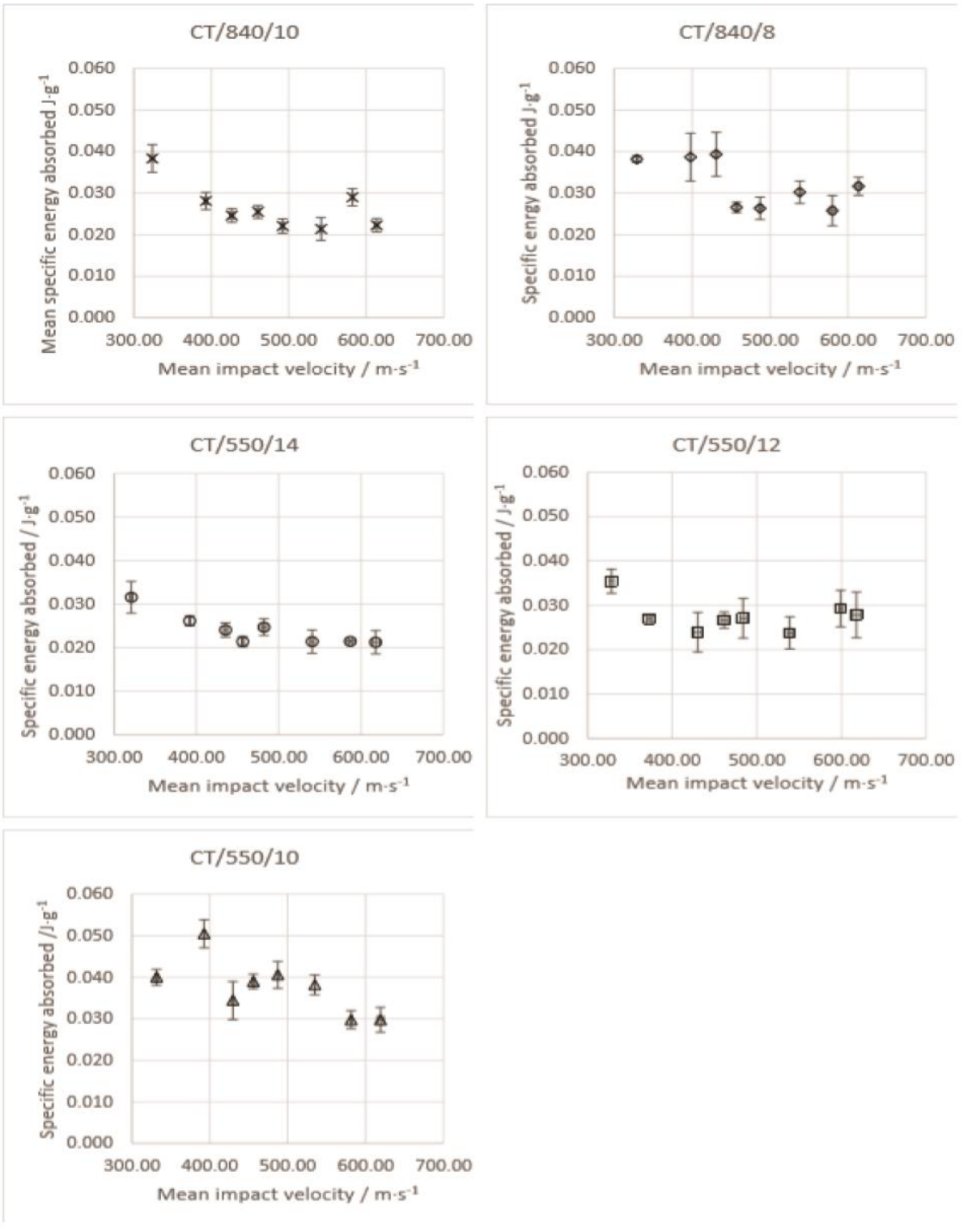

Fig.3. - SEA profiles for single-ply para-aramid fabrics individually labelled with fabric type at top. 

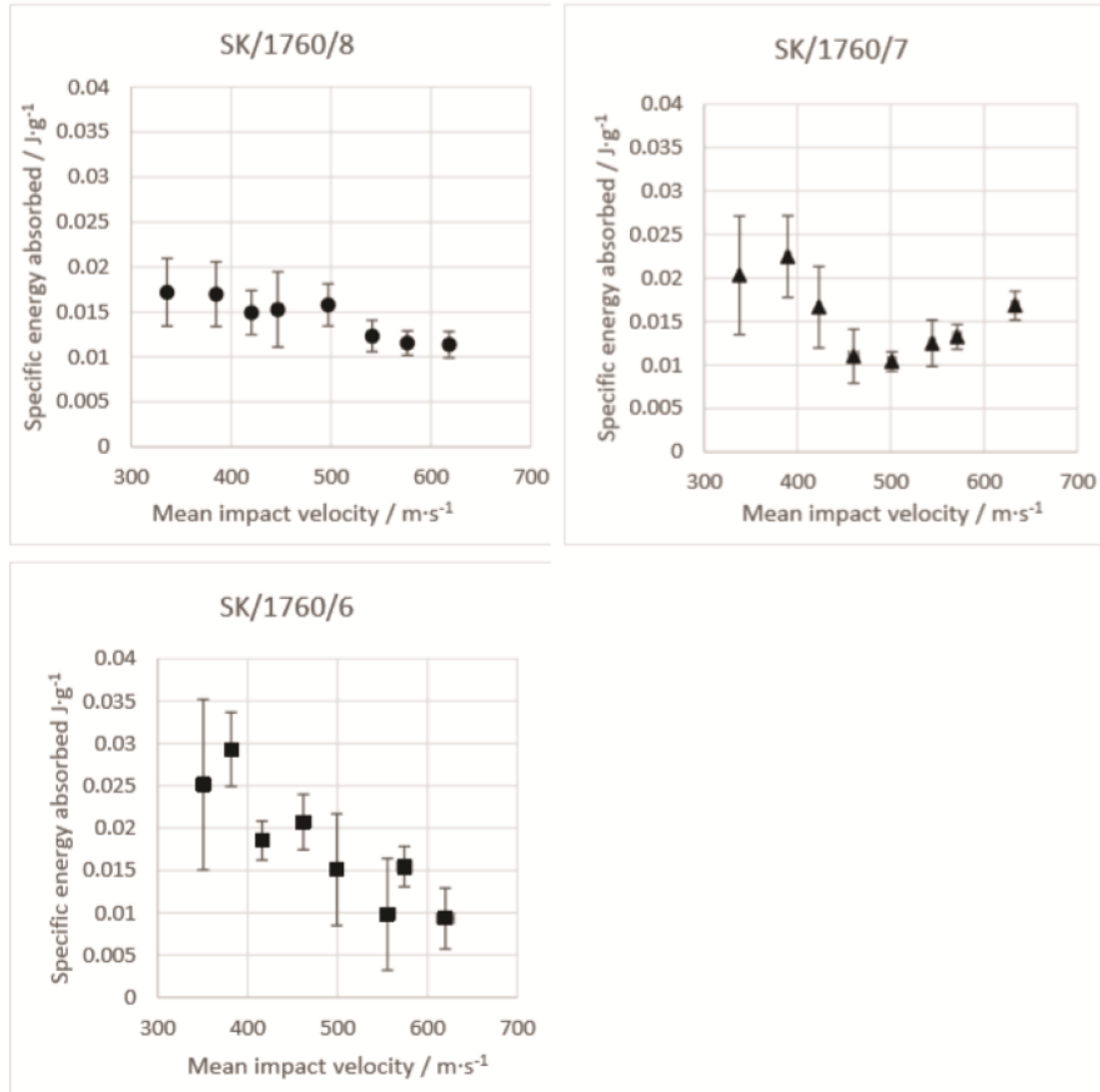

Fig.4. - SEA profiles for single-ply UHMWPE fabrics individually labelled with fabric type at top.

\subsection{Critical velocity, failure mode and cover factor}

High speed video (HSV) of each impact was analysed to determine whether the reduction in SEA was related to the Critical Velocity of the single-ply fabrics. The defeat of the fabric was observed to establish how the fabrics failed, noting fractured yarns, yarns pulled from the weave and the initiation of a transverse wave. HSV revealed a distinct variation in impact response with velocity, illustrated in Fig. 5. Above the critical velocity, the yarns failed instantaneously, typical of a shear failure, and, below this velocity, the fabric deflected and the yarns failed under a tensile failure or were pulled from the weave. These failure modes were in keeping with the failure modes reported by Susich et al. [25] and Lee et al. [26]. It was inferred from the association between experimental observation and published literature that a high velocity impact is equivalent to the high strain rate response experienced at the front of an armour system. It was similarly inferred that a low velocity impact is equivalent to 
the low strain rate response indicative of the rear of an armour system. Given these mixed failure modes, it is difficult to define a precise critical velocity for each fabric.

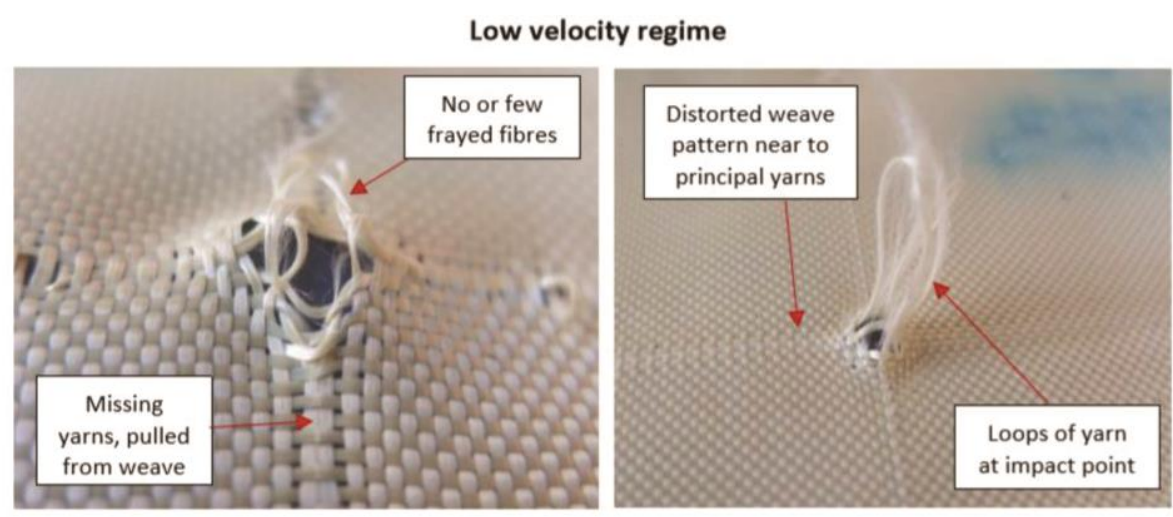

High velocity regime

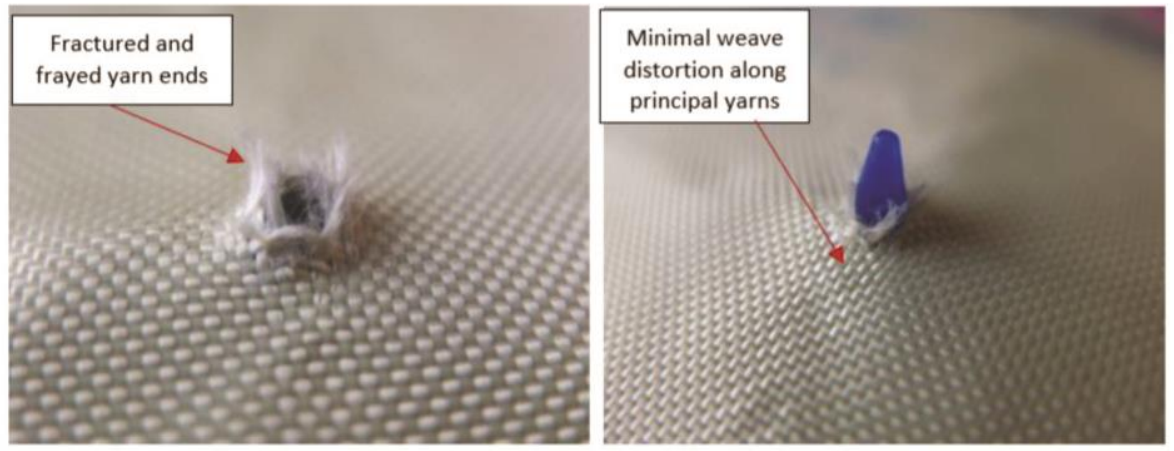

Fig.5. - Typical impact damage: Low velocity regime (top), High velocity regime (bottom).

Therefore, Table 2 summarises a Critical Velocity range, bounded by the lowest velocity fracture failure and the highest velocity slip failure observed. For any given $\mathrm{C}_{\mathrm{fab}}$, the UHMWPE SK/1760/XX fabrics had higher critical velocity than both para-aramid fabric sets which can be linked to the strain wave velocity of single yarns (Fig. 12) which exceeded that of para-aramids by $16-24 \%$. For all fabric sets the critical velocity reduces with increasing $\mathrm{C}_{\mathrm{fab}}$ suggesting that the higher $\mathrm{C}_{\mathrm{fab}}$ fabrics are more susceptible to early failure from the higher strain rate loading associated with higher impact velocities. While limited statistical significance could be drawn between the differences in energy absorbed and the projectile impact velocity, the footage supports the connection between SEA and the critical velocity. The reduction in critical velocity with $\mathrm{C}_{\mathrm{fab}}$ suggests that the strain wave velocity also reduces with $\mathrm{C}_{\mathrm{fab}}$ contrary to Stempien's findings [27] and is corroborated by the transverse wave of 
each fabric (Fig. 12). No values for percentage crimp were given in Stempien's paper and as such this disparity could be the result of increased tension in the warp yarns as the weft density increases. In this study, the thread count of fabrics were increased only in the weft direction, which would limit the crimp in the warp yarns, effectively straightening them [28]. A straight yarn under tension would then dissipate the strain more rapidly, as it will not need to uncrimp prior to propagating the strain. If this assumption is correct it could be inferred that critical velocity decreases with higher $\mathrm{C}_{\mathrm{fab}}$ in this study due to their higher percentage crimp (Table 2) and hence hindering the dissipation of strain energy from the point of impact causing the strain to accumulate more rapidly and the principal yarns to fail earlier.

Table 2: Critical Velocity range and crimp for all fabrics

\begin{tabular}{lllll}
\hline Fabric & $\begin{array}{l}\text { Thread count } \\
\text { xWeft / yarns·cm-1 }\end{array}$ & $\mathrm{C}_{\mathrm{fab}}$ & Crimp (\%) & $\begin{array}{l}\text { Critical Velocity range } \\
(\mathrm{HSV}){\mathrm{m} . \mathrm{s}^{-1}}^{-1}\end{array}$ \\
\hline $\mathrm{CT} / 840 / 10$ & $10 \mathrm{X} 10$ & 0.89 & 4.97 & $389-389$ \\
$\mathrm{CT} / 840 / 8$ & $8 \mathrm{X} 8$ & 0.78 & 2.14 & $453-457$ \\
$\mathrm{CT} / 550 / 14$ & $14 \mathrm{X} 14$ & 0.93 & 5.93 & $316-390$ \\
$\mathrm{CT} / 550 / 12$ & $12 \mathrm{X} 12$ & 0.86 & 3.78 & $382-404$ \\
$\mathrm{CT} / 550 / 10$ & $10 \times 10$ & 0.76 & 2.25 & $427-455$ \\
$\mathrm{SK} / 1760 / 8$ & $8 \times 8$ & 0.97 & 16.18 & $328-520$ \\
$\mathrm{SK} / 1760 / 7$ & $7 X 7$ & 0.92 & 14.32 & $429-464$ \\
$\mathrm{SK} / 1760 / 6$ & $6 \mathrm{X} 6$ & 0.84 & 9.48 & $496-503$ \\
\hline
\end{tabular}

A comparison of the SEA of the fabrics above and below the critical velocities is shown in

Fig. 6. The fabric with the greatest SEA both above and below its critical velocity was CT/550/10 closely followed by CT/840/8. These two fabrics have the lowest fabric $\mathrm{C}_{\mathrm{fab}}$ of all the fabrics tested (Table 1). In addition, their $\mathrm{C}_{\mathrm{fab}}$ of 0.76 and 0.78 are both close to the optimum $\mathrm{C}_{\mathrm{fab}}$ of 0.75 proposed by Figucia [29]. The trend between $\mathrm{C}_{\mathrm{fab}}$ and the SEA of the fabric must be explained within the confines of the energy absorption mechanisms available. These have been summarised to include energy dissipation through: yarn fracture; strain propagation along the impacted yarns; the relative movement of yarns and fibres and through the kinetic response of the fabric [30]. 

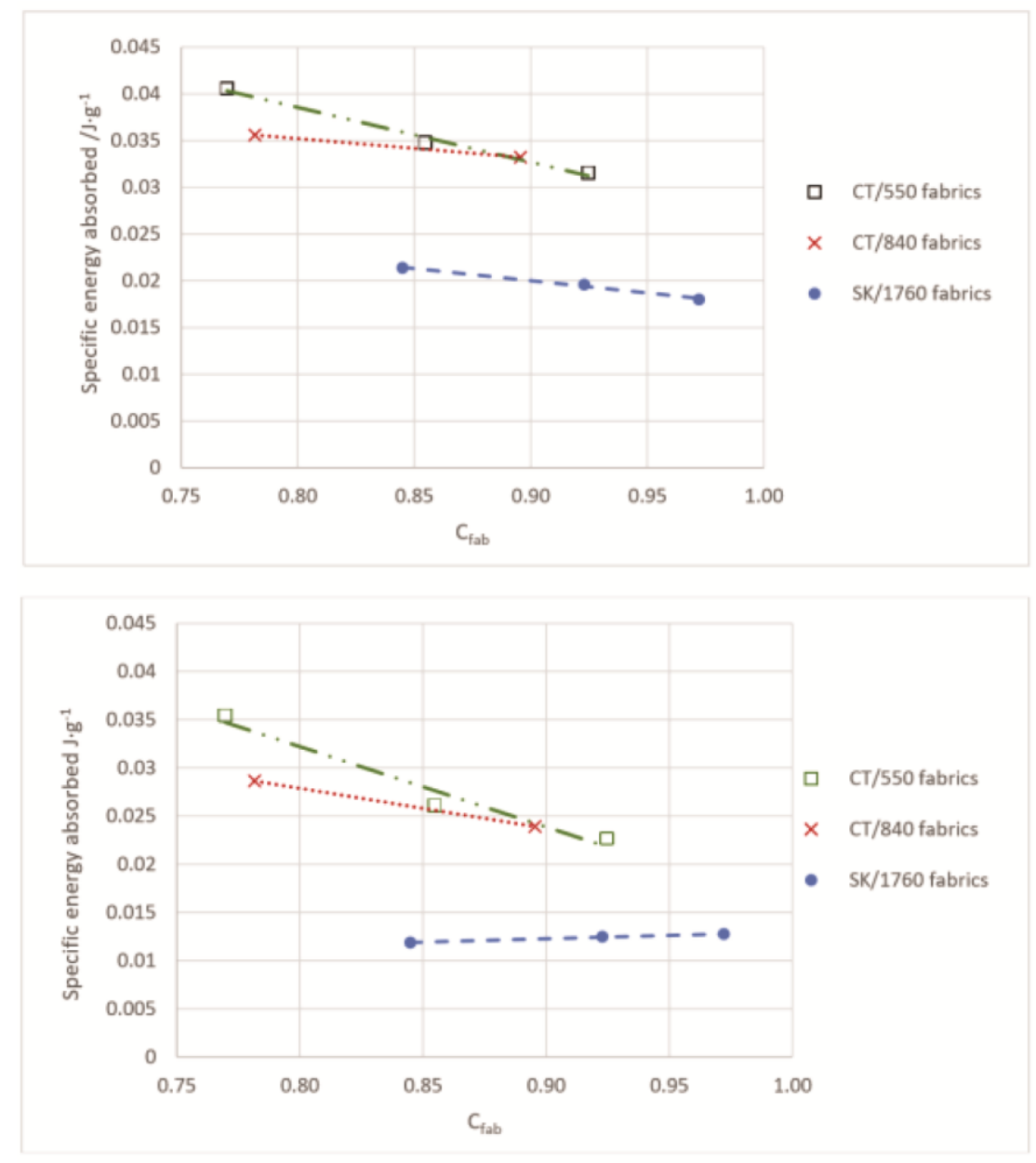

Fig.6. - Relationships between SEA and $\mathrm{C}_{\mathrm{fab}}$ for all yarn types bellow (top) and above (bottom) the critical velocity.

To understand these trends, the mean actual energy absorbed $\left(E_{a b s}\right)$ for both failure modes was calculated for each fabric based of the failure mode identified through HSV, shown in Fig. 7. The $E_{a b s}$ rather than SEA allows comparison of the relative energy absorbed through yarn fracture and the frictional effects of the weave between fabrics of a given yarn type. These features are not clear when considering energy absorption performance only in terms of mass efficiency. As expected, given the variation in SEA either side of the critical velocity, there is a significant difference in $E_{a b s}$ under the two failure modes for each fabric type. Above the Critical Velocity, the energy absorption mechanisms are limited to the accumulation of strain in the impacted yarns leading to yarn fracture. Previous studies by 
Rodriguez [31] and Tan [32] have looked at the strain rate dependency of the failure stress and strain for both UHMWPE and para-aramid polymers.

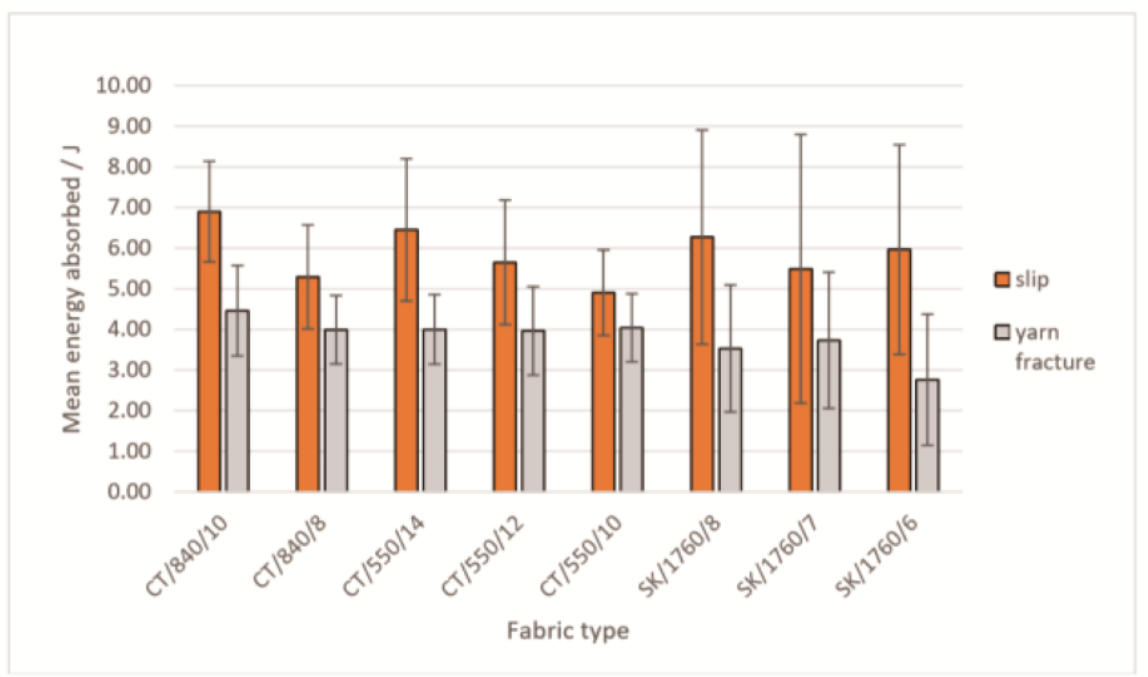

Fig.7. $-E_{a b s}$ under the two failure modes: yarn pull and slip failure and yarn fracture.

Both Rrodriguez and Tan conclude that the polymer's modulus, failure strain and failure stress increase with strain rate. While this data is not available for the yarns tested, it can be concluded that the energy absorbed above the critical velocity depends upon the linear density, dynamic tenacity and strain of each yarn. The volume of the yarn strained will depend upon the strain wave velocity within the yarn and the number of yarns impacted for each fabric where the number of impacted yarns is dictated by the $\mathrm{C}_{\mathrm{fab}}$ and the yarn diameter with the more densely woven structures having effectively a greater volume of yarns in the projectile's path. From Fig. 7 under the yarn fracture failure mode, the $E_{a b s}$ for these fabrics is about equal at approximately $4 \mathrm{~J}$ for all CT fabrics contrary to the expected higher net energy absorption for high $\mathrm{C}_{\mathrm{fab}}$ fabrics given the additional yarns. This incongruity is explained by an increased strain wave velocity in the lower $\mathrm{C}_{\mathrm{fab}}$ fabrics as suggested by their higher Critical velocities. In this regard, the displacement of the strain wave front along the impacted yarns will travel further prior to the yarn fracturing, each individual yarn absorbing greater energy and compensating for the fewer yarns fractured. 
Below the Critical Velocity, secondary energy absorption mechanisms are engaged. Based on the failure modes identified from the HSV, all the fabrics showed an increased energy absorption capacity under a slip failure rather than yarn fracture of between $1 \mathrm{~J}$ and $3 \mathrm{~J}$ (Fig. 7). HSV revealed the early failure of the UHMWPE SK/1760/XX fabrics in the low velocity regime. Whilst the para-aramid fabrics tended to engage with the projectile casting a net across its path, the projectile was able to roll off of the larger diameter SK/1760 yarns. This is likely to be augmented by the secondary yarns migrating down the principal yarns away from the point of impact allowing an easy opening through which the projectile may pass and could explain the lower SEA across all velocity brackets. For the lower $\mathrm{C}_{\text {fab }}$ para-aramid fabrics, CT/550/10 and CT/840/8, the benefit transitioning between failure modes was less pronounced than for the higher $\mathrm{C}_{\text {fab }}$ fabrics; the slip failure showing only a $21 \%$ and $33 \%$ increase compared to a $55 \%$ and $61 \%$ for the higher $\mathrm{C}_{\mathrm{fab}}$ fabrics. This indicates that the secondary energy absorption mechanisms dominated in the higher $\mathrm{C}_{\mathrm{fab}}$ fabrics.

Ballistic testing has shown that the SEA below the Critical Velocity also decreased with increasing $\mathrm{C}_{\mathrm{fab}}$ and that the SK/1760 fabrics had a significantly lower SEA than the paraaramids (Fig. 6). If the $E_{\text {abs }}$ below the Critical Velocity was governed by strain development and fibre fracture, it would follow a similar pattern to the SEA above the Critical Velocity and potentially decrease more rapidly with $\mathrm{C}_{\mathrm{fab}}$ as the strain wave velocity in the fabrics reduces. Instead, this trend shows a more gradual decline than above the critical velocity (Fig. 6). To illustrate this, the data presented in Fig. 6 is shown as $E_{\text {abs }}$ rather than SEA in Fig. 8. 


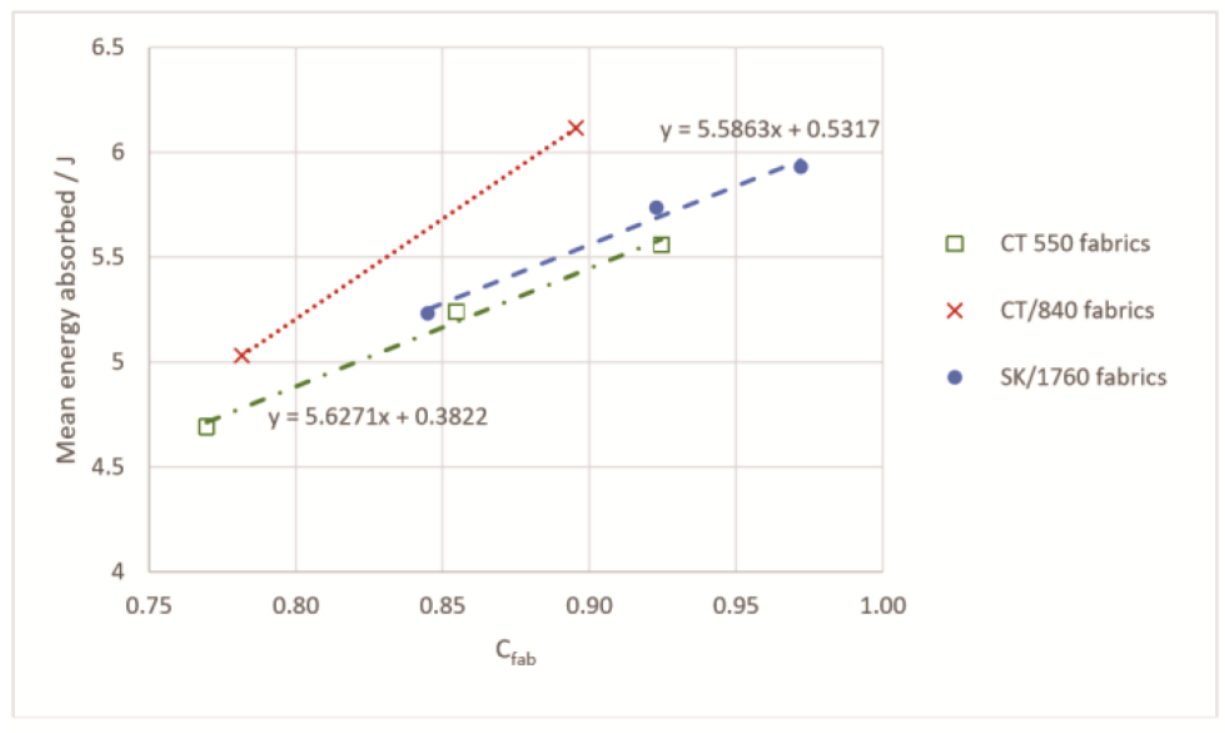

Fig.8. - Relationship between net energy absorbed below the Critical Velocity and $\mathrm{C}_{\text {fab }}$ for the three fabric sets

It can clearly be seen that Eabs actually increases with $\mathrm{C}_{\text {fab }}$ for all fabric sets; a feature that is hidden when mass efficiency is considered for SEA. Although partitioning of energy absorption between the various mechanisms means that exact contribution of each is unknown, the secondary mechanisms below the Critical Velocity must be responsible for the additional energy absorbed. Previous numerical studies have all shown that these secondary energy absorption mechanisms are highly sensitive to the inter-yarn friction of the weave. These mechanisms are summarised as yarn pull out, yarn migration from the point of impact, shearing at yarn crossovers; and the global deflection of the fabric [33-36]. It has further been shown that for plain woven fabrics of any given yarn type that the energy absorption would increase with thread count as the friction within the weave increased [33]. Within the impact velocities tested, the increase in energy absorbed through these secondary energy absorption mechanisms was insufficient to compensate for the additional mass held by higher $\mathrm{C}_{\mathrm{fab}}$ fabrics.

\subsection{Layered system}

Determination of the Critical Velocity and SEA data above and below the Critical Velocity for the single-ply fabrics has resulted in a generalisation that the lower $\mathrm{C}_{\mathrm{fab}}$ fabrics are best 
front, middle and rear of a layered soft armour system. Whilst the lightest CT/550/10 fabric showed a superior energy absorption capacity as a mean value above and below its Critical Velocity, this may vary across the 8 impact velocity brackets tested which the previous generalisation fails to account for. To address this, fabrics are considered on a layer-to-layer basis by a theoretical spaced system, i.e. a system consisting of layers of fabric separated so that no single layer interacts with a successive layer within the system. This idealised system undergoes an impact from a projectile of known size, shape and impact velocity. From the energy absorption data presented, the first layer of the system would be a fabric with maximum energy absorption capacity for that impact velocity. Each successive layer would be selected dependent on the residual velocity of the projectile after it has emerged from the previous layer thus creating a hybridised system. Assuming the projectile to be the $5.56 \mathrm{~mm}$ steel sphere impacting the first layer at $620 \mathrm{~m} \cdot \mathrm{s} 1$, Fig. 9 presents theoretical spaced systems for each fabric type and for an optimised hybrid system detailing the number of layers and corresponding mass per unit area for each system.

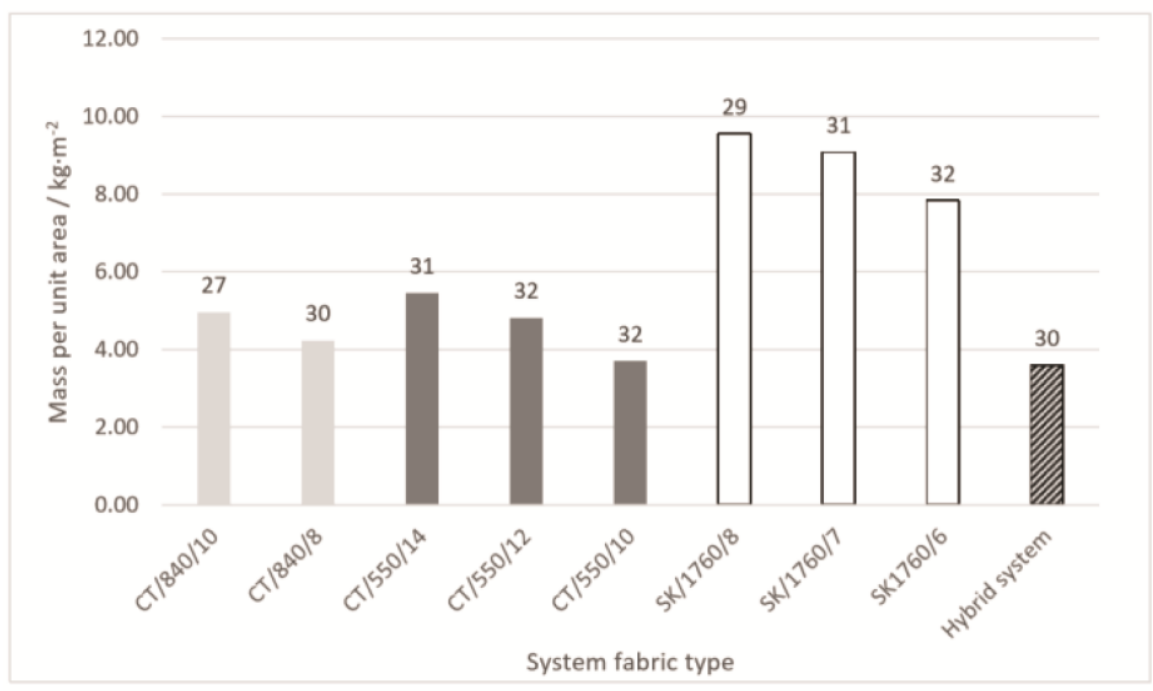

Fig.9. - Mass per unit area of mono lithic and hybrid spaced armour system required to

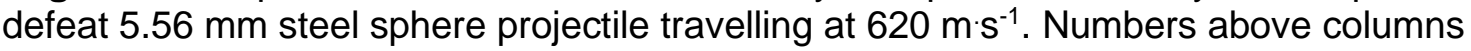
indicate total number of layers for each system.

When considered in this way, it is apparent that the CT/550/10 is the best fabric choice for a monolithic system. It has the lowest mass per unit area, theoretically defeating the projectile 
with 32 layers of fabrics totalling $3.7 \mathrm{~kg} \cdot \mathrm{m}-2$. The nearest competitor to the $\mathrm{CT} / 550 / 10$ system is the other lower $\mathrm{C}_{\text {fab }}$ para-aramid CT/840/8 weighing an additional $540 \mathrm{~g} \cdot \mathrm{m}-2$, or 15\%. This would agree with the findings of both Cunniff [20] and Figucia [29], which independently concluded that it is better to have many lighter layers rather than fewer heavier layers within an armour system.

The SEA capacity of the para-aramid fabrics was significantly higher than the UHMWPE fabrics tested. This was a trend that carried across all impact velocities and is reflected in the relative mass of the UHMWPE and para-aramid systems. The UHMWPE fabrics were made from higher linear density yarn and produced fabrics with a higher mass per unit area. When considering SEA, the UHMWPE fabrics would have had to absorb 2 - 3 times the actual energy per layer from the projectile to match the lighter para-aramid fabrics. Above the Critical Velocity, any layer-to layer-interaction should be localised and limited to the loading of the fabric layers at the point of impact. In this respect, any system effects noted must be linked to the compression of the fabric layers directly in front of the projectile, which may have an effect on their critical breaking strength or the relative strain through successive layers of the system.

\subsection{Transverse wave interference}

An example of transverse wave images taken from the vertical high-speed camera for tested fabrics at both low and high velocity can be seen in Fig. 10. These images highlight a clear difference in transverse wave formation of the same fabric under different velocity regimes and is important to analyse to understand how subsequent layers may interact. Representative images of transverse wave and strain wave measurement, including subsequent DIC, can be seen in Fig. 11. 

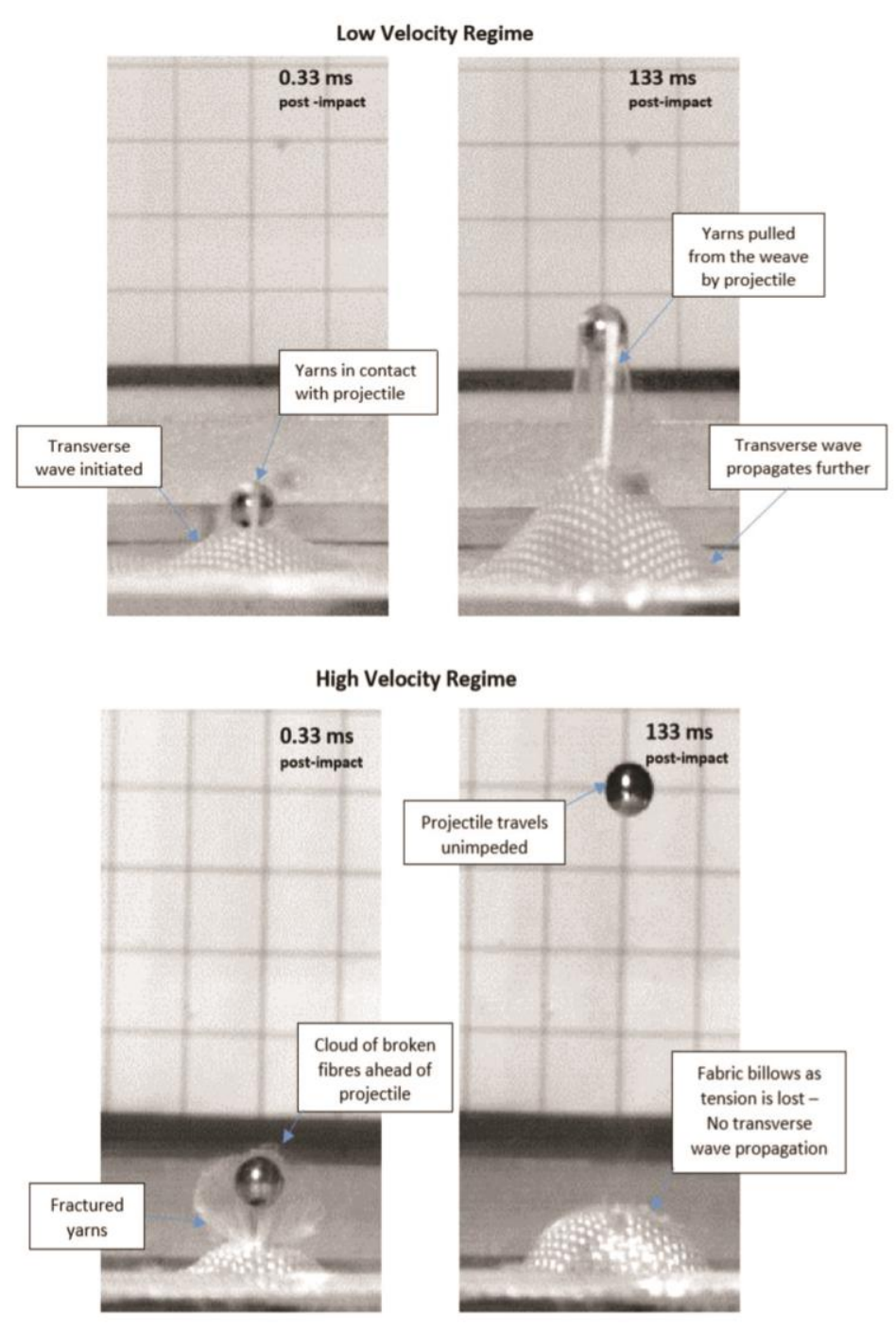

Fig.10. - Single ply CT/840/10 fabric 1 and 3 frames post-impact under low and high velocity regimes. Projectile impacting at $331 \mathrm{~m} \cdot \mathrm{s}^{-2}$ (top) and $621 \mathrm{~m} \cdot \mathrm{s}^{-2}$ (bottom) 

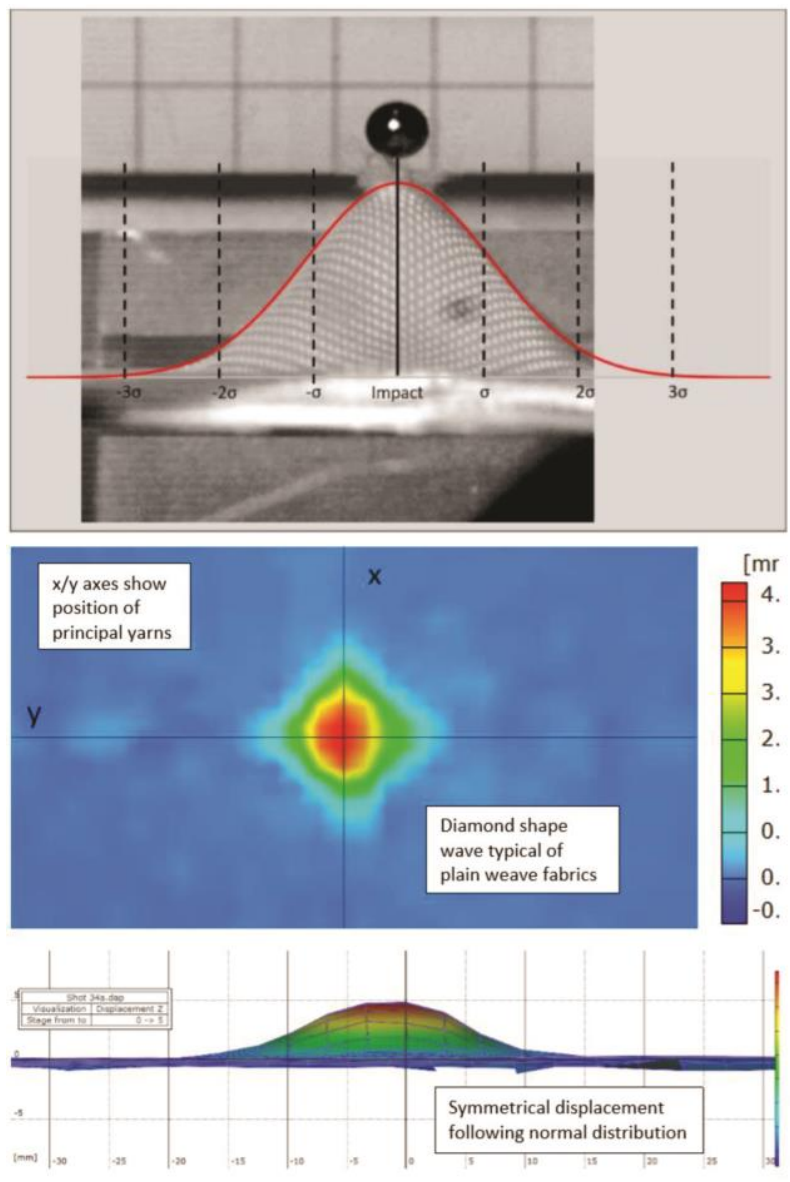

Fig.11. - Transverse fabric deflection wave overlaid with normal distribution (top) and DIC output from high speed images.

Below the Critical Velocity, there is potential for further interference between layers as the transverse waves propagate. The transverse wave velocities for both single yarns and fabrics were measured and the single yarn data was interpolated to give the wave velocity at $340 \mathrm{~m} \cdot \mathrm{s}-1$, which was compared to DIC analysis for the fabrics. Wave velocities for single yarns and fabrics are shown in Fig. 12 and Fig. 13 respectively. 


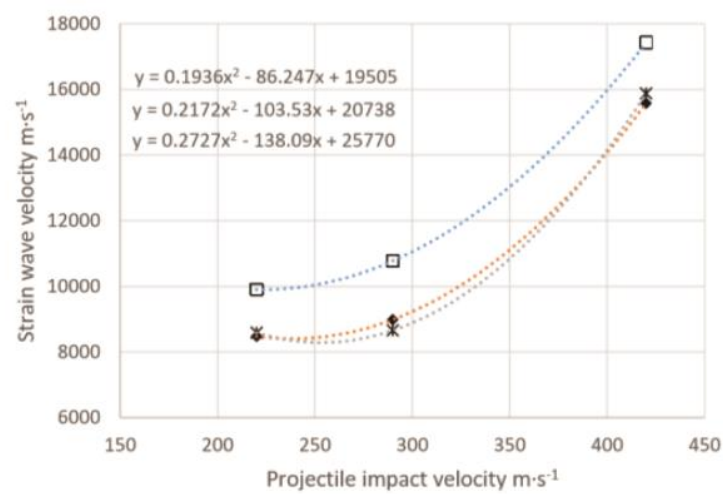

ㅁ SK76 $1760 \mathrm{dTex}$

- $\quad$ CT 2000840 dTex

* CT 2040550 dTex

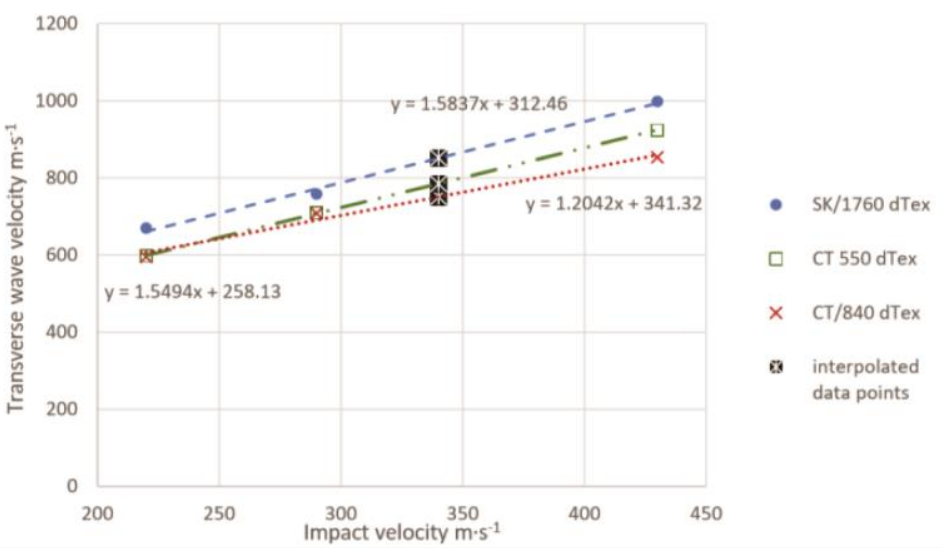

Fig.12. - (Top) relationship between strain wave velocity along yarn and projectile impact velocity and (bottom) relationship between impact velocity and transverse wave velocity of all single yarn types.

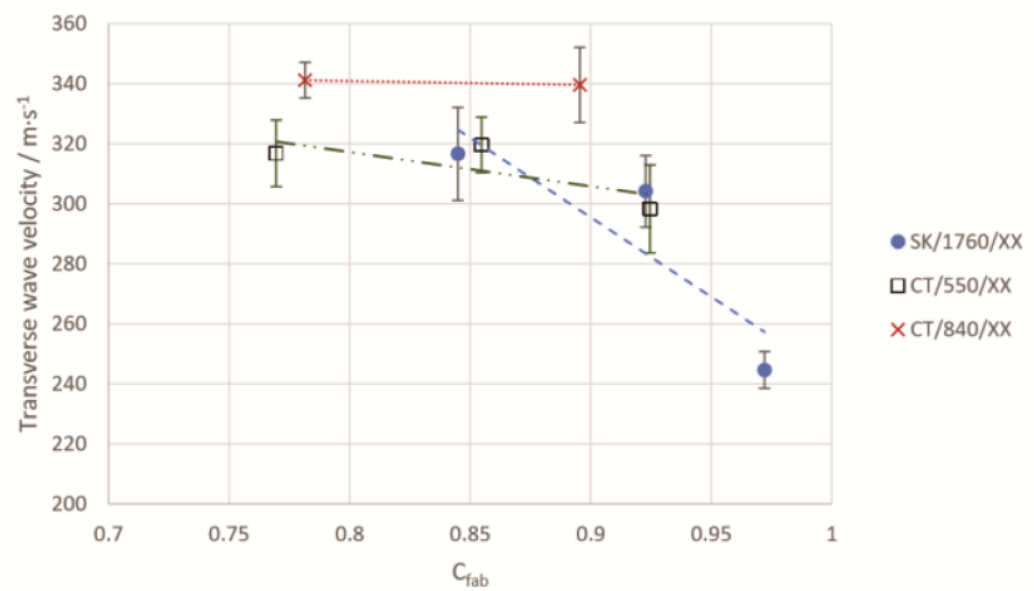

Fig.13. - Relationship between transverse wave velocity and $\mathrm{C}_{\mathrm{fab}}$ for each fabric. 
Results show that UHMWPE SK 1760 yarn had both a higher strain wave velocity and transverse wave velocity than both the para-aramid yarns. It is evident that fabric transverse wave velocities were distinctly lower than the transverse wave velocities of their constituent yarns with UHMWPE fabrics having a lower transverse wave velocity than para-aramid fabrics at all $\mathrm{C}_{\text {fab }}$. Furthermore the transverse wave velocity of a fabric increased with decreasing $\mathrm{C}_{\mathrm{fab}}$ for all fabric sets.

Theory suggests that the transverse wave velocity for both single yarn and fabric are dependent upon the velocity of the preceding strain wave along the yarns [37]. There was direct evidence of this for the single yarns, where both the transverse wave and strain wave velocity increased with impact velocity. While the strain propagation could not be directly measured for the fabrics, there was indirect evidence of this dependency. The increase in Critical Velocity with decreasing $C_{\text {fab }}$ indicated that the strain wave velocity was greater in the low $\mathrm{C}_{\mathrm{fab}}$ fabrics, which coincided with the decrease in transverse wave velocity with $\mathrm{C}_{\mathrm{fab}}$ seen through the DIC analysis.

The reduction in transverse wave velocity from yarn to fabric and with increasing $\mathrm{C}_{\mathrm{fab}}$ confirms that the fabric parameters inhibit the propagation of the strain and transverse waves. Furthermore, there is evidence to suggest that the weave architecture has more influence on wave propagation than the yarn elastic modulus amongst the fabrics tested. Fig. 14 shows the transverse wave velocity in relation to the percentage crimp of each fabric. Based on yarn elastic modulus alone, the UHMWPE fabrics should exhibit a higher transverse wave velocity as they did in the single yarn tests (Fig. 12). 


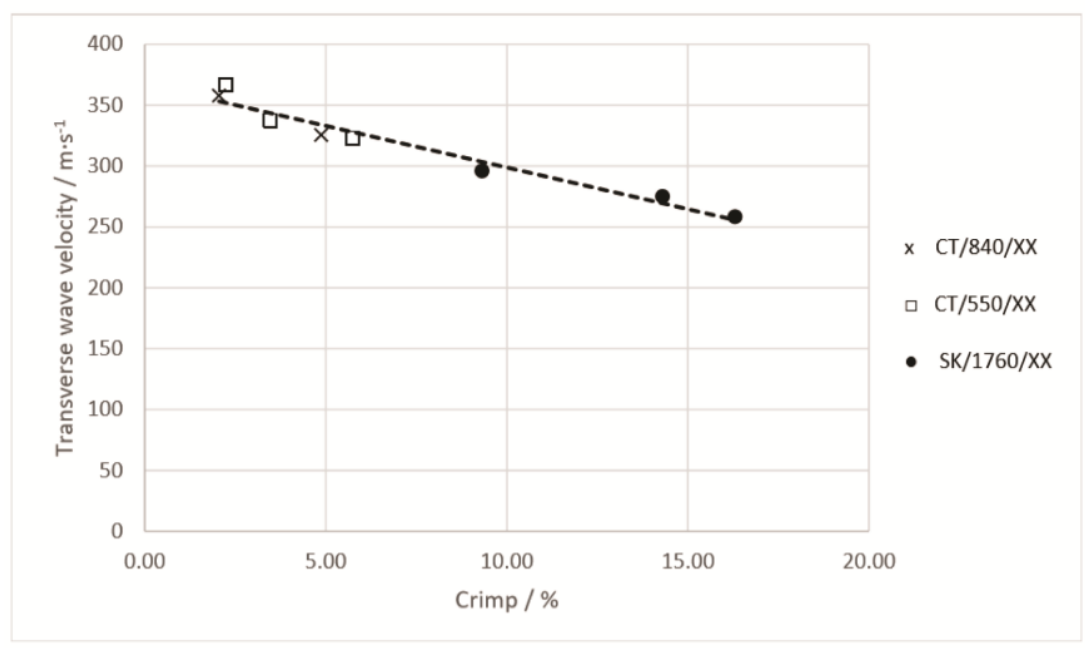

Fig.14. - Relationship between transverse wave velocity and percentage crimp for all fabrics.

However, the UHMWPE fabrics were manufactured of a high linear density yarn and were shown to have a much higher percentage crimp than the finer para-aramid fabrics (Table 2). Consequently, both strain and transverse wave must have been retarded more severely in the UHMWPE fabrics as a result of the fabric architecture overriding the advantage of their higher elastic modulus.

The dependency on the fabric crimp shows that the strain and transverse wave velocities can be controlled by fabric geometry, which could be used to manipulate a layered system response.

With respect to designs for a hybridised system, the layers could be forced to interact with each other by placing fabrics of a given yarn type in order of increasing or decreasing $\mathrm{C}_{\mathrm{fab}}$. If a fabric of higher $\mathrm{C}_{\mathrm{fab}}$ were placed on the strike face, the transverse wave would pass more slowly across the surface of this fabric than the successive layers and all layers would propagate the transverse wave freely, illustrated in Fig. 15a. Alternatively, the lowest $\mathrm{C}_{\mathrm{fab}}$ fabric could be placed at the strike face and its faster transverse wave would drive the successive higher $\mathrm{C}_{\mathrm{fab}}$ layers in the system (Fig. 15b). Zhou et. al [19] has shown that hybridisation of layers between aramid and UHMWPE can result in increased energy 
absorption. Further development of this hybridisation using varying cover factors as well as material could see further improvements in hybridised systems.

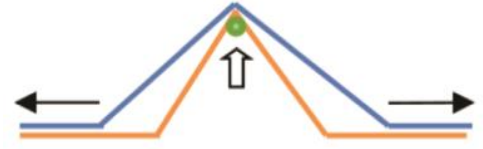

Transverse waves propagate freely in all layers

a. Higher $\mathrm{C}_{\mathrm{fab}}$ strike face

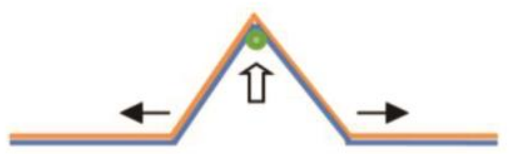

Rear layers confine preceding layers

b. Lower $\mathrm{C}_{\mathrm{fab}}$ strike face

Fig.15. -Theoretical response of multiple ply plain weave systems with a. increasing $\mathrm{C}_{\mathrm{fab}}$ and b. decreasing $\mathrm{C}_{\mathrm{fab}}$.

The transverse wave velocities could also be manipulated using fabrics with different constituent yarn types, as was intended by Cunniff (21) when testing the 2 ply UHMWPE/para-aramid system. However, these results have shown that it would be incorrect to use the elastic modulus alone to set the relative transverse wave velocities of each layer without considering the weave architecture; for this study, the transverse wave in the UHMWPE fabrics travelling more slowly than the para-aramids despite their higher modulus.

\section{Conclusion}

It was identified from single-ply impact tests that the lower $\mathrm{C}_{\mathrm{fab}}$ fabrics $(0.76-0.84)$ within each fabric set had:

- the highest SEA across the impact velocities tested;

- the highest Critical Velocities; and

- the greatest transverse wave velocities.

Of the low $\mathrm{C}_{\text {fab }}$ fabrics, the $\mathrm{CT} / 550 / 10$ fabric had the highest mean SEA of all fabrics across the range of impact velocities tested. It was determined that this fabric would provide the 
lowest mass solution for a homogenous spaced system in which the layers act independently of one another. Based on the single-ply SEA data, only a small mass efficiency could be gained by hybridising the system to include the CT/840/8 fabric, which proved superior in the highest velocity bracket; the hybrid system weighing only $3 \%$ less. The UHMWPE fabrics were not considered suitable for a woven hybrid system as they had a significantly lower SEA compared to all the para-aramid fabrics.

It was speculated, but not verified, that at velocities below $320 \mathrm{~m} \cdot \mathrm{s}-1$ the balance of energy absorption would change in favour of the higher $\mathrm{C}_{\mathrm{fab}} /$ higher friction fabrics, as the peak strain in the principal yarns reduces and frictional effects increase. If correct, a hybrid system would benefit from higher $\mathrm{C}_{\text {fab }}$ para-aramid fabrics $(>0.85)$ as rearward layers. However, as a stacked system with layers combined, the higher $\mathrm{C}_{\text {fab }}$ fabrics have slower transverse wave propagation which, if placed at the rear of a system, may inhibit the motion of the lower $\mathrm{C}_{\mathrm{fab}}$

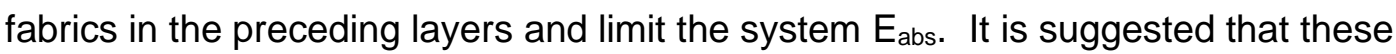
conflicting theories should be tested and discussed further.

\section{Acknowledgements}

The authors would like to thank Axis Composites for weaving test fabrics. Further thanks to Ulster University and Northern Ireland Advanced Composites and Engineering (NIACE) Centre for support and provision of testing equipment.

Declarations of interest: The authors declare that they have no conflict of interest.

\section{Funding}

This work was funded by a Department for Employment and Learning (DEL) CAST award and supported by DSTL. 


\section{References}

[1]Laible R, Barron E. History of Armour. In: Laible R, editor. Methods and Phenomena 5: Ballistic Materials and Penetration Phenomena. . 1st ed. Amsterdam: Elsevier Scientific Publishing Company; 1980. p. 9-40.

[2]Explosive Injury. 2011.

[3]Bashford D. Soft Armor, Its Beginning, Development and Possible Value. Helmets and Body Armor in Modern Warfare. 1st ed.: Yale University Press; 1920.

[4]Laible R. Fibrous Armour. In: Laible R, editor. Methods and Phenomena 5: Ballistic Materials and Penetration Phenomena. 1st ed. Amsterdam. 1st ed. Amsterdam: Elsevier Scientific Publishing Company; 1980. p. 73-115.

[5]Yang H. Kevlar aramid fiber. Chichester: Wiley; 1993.

[6]Karahan M, Kuş A, Eren R. An investigation into ballistic performance and energy absorption capabilities of woven aramid fabrics. International Journal of Impact Engineering 2008 June 2008;35(6):499-510.

[7]McDonald J. Medieval Warfare armour and shields. 2015; Available at: http://www.medievalwarfare.info/armour.htm. Accessed June 17th, 2018.

[8]Riley-Smith B. Soldiers complain new body armour makes it difficult to get up from the ground. . 2016.

[9]UK MOD. Combat Body Armour. 2016; Available at:

http://www.army.mod.uk/equipment/23216.aspx. Accessed July 28th, 2017.

[10]Erwin S. Army has few options to lessen weight of body armor. 2009.

[11]Savage-Knepshield P, Martin J, Lockett IJ, Allender L. Desigining Soldier Systems: Current Issues in Human Factors. 1st ed. Surrey, UK: Ashgate Publishing Ltd; 2012.

[12]Carter R, Cheuvront S, Williams J, Stephenson L, Sawka M, Amoroso P. Epidemiology of Hospitalisations and Deaths from Heat Illness in Soldiers. Medicine and Science in Sports and Exercise 2005;37(8):1338-1344.

[13]SEA. Reducing The Burden on the Dismounted Soldier (RBDS). 2010; Available at: https://www.sea.co.uk/Docs/landandair/cs RBDS\%20jan\%2010.pdf. Accessed September 22nd, 2017.

[14]Walkinshaw L. Travelling light: reducing the burden on the close-combat soldier. 2012; Available at: http://www.army-technology.com/features/featuredssi-icg-des-dstl-soldier-asasystem/. Accessed September 22nd, 2017.

[15]Cavallaro P. Soft Body Armor: An Overview of Materials, Manufacturing, Testing, and Ballistic Impact Dynamics. 2011. 
[16]Prosser R. Penetration of Nylon Ballistic Panels By Fragment-Simulating Projectiles. Part 2: Mechanisms of Penetration. Textile Research Journal 1988;58:161-165.

[17]From filaments to fabric packs, Simulating the performance of textile protection systems. . ADM002075; 2006.

[18]Thomas J, HL., inventor. AnonymousAnonymous Layered Ballistic Resistant Material. Georgia/US patent. 2004 .

[19]Zhou Y, Hou J, Gong X, Yang D. Hybrid panels from woven Kevlar and Dyneema fabrics against ballistic impact with wearing flexibility. The Journal of The Textile Institute 2018;109(8):1027-1035.

[20]Cunniff $P$. An analysis of the systems effects in woven fabrics under ballistic impact. Textile Research Journal 1992;62(9):495-509.

[21]Yang Y, Chen X. Influence of fabric architecture on energy absorption efficiency of soft armour panel under ballistic impact. Composite Structures 201915 September 2019;224:111015.

[22]Azrin Hani AR, Roslan A, Mariatti J, Maziah M. Body armour technology: a review of materials, construction techniques and enhancement of ballistic energy absorption.

Advanced Materials Research 2012;488-489:806-812.

[23]Nilakantan G, Horner S, Halls V, Zheng J. Virtual ballistic impact testing of Kevlar soft armor: Predictive and validated finite element modeling of the V0-V100 probabilistic penetration response. Defence Technology 2018 June 2018;14(3):213-225.

[24]Guo Z, Chen W, Zheng J. A semi-empirical design parameter for determining the inelastic strike-face mass fraction of soft armor targets. International Journal of Impact Engineering 2019 March 2019;125:83-92.

[25]Susich G, Dogliotti L, Wrigley A. Microscopical study of multilayer nylon body armor panel after impact. Textile Research Journal 1958;28(5):361-377.

[26]Lee B, Walsh T, Won S, Song J, Mayer A. Penetration Failure Mechanisms of ArmorGrade Fiber Composites under Impact. Journal of Composite Materials 2001;35(18):16051633.

[27]Stempien Z. Influence of a Woven Fabric Structure on the Propagation Velocity of a Tension Wave. Fibres and Textiles in Eastern Europe 2007;15(5-6):174-178.

[28]Sule G. Investigation of bending and drape properties of woven fabrics and the effects of fabric constructional parameters and warp tension on these properties. . Textile Research Journal 2012;82(8):810-819.

[29]Figucia F. Energy absorption of Kevlar® Fabrics Under Ballistic Impact. ADA090390 1980:29-41.

[30]Termonia Y. Impact Resistance of Woven Fabrics. Textile Research Journal 2004;74(8):723-729. 
[31]Rodriguez J, Chocron I, Martinez M, Sánchez-Gálvez V. High strain rate properties of aramid and polyethylene woven fabric composites. Composites Part B: Engineering 1996;27(2):147-154.

[32]Tan V, Zeng X, Shim V. Characterization and constitutive modeling of aramid fibers at high strain rates. International Journal of Impact Engineering 2008;11(35):11-1303-1313.

[33]Sadegh A, Cavallaro P. Crimp imbalanced protective (CRIMP) fabrics: An analytical investication into the relationship between crimp contents, energy absorption and fabric ballistic performance. ADA530736 2010.

[34]Duan Y, Keefe M, Bogetti T, Cheeseman B, Powers B. A numerical investigation of the influence of friction on energy absorption by a high-strength fabric subjected to ballistic impact . International Journal of Impact Engineering 2006;32(8):1299-1312.

[35]Zeng X, Shim V, Tan V. Influence of boundary conditions on the ballistic performance of high-strength fabric targets. International Journal of Impact Engineering 2006;32(1-4):631642.

[36]Zhou Y, Chen X. Numerical Investigations into the Response of Fabrics Subjected to Ballistic Impact. Journal of Industrial Textiles 2016;45(6):1520-1547.

[37]Smith J, McCrackin F, Schiefer H. Stress-Strain relationships in yarns subjected to rapid impact loading : Part V Wave propagation in long textile yarns impacted transversely. Textile Research Journal 1958;28(1):288-302. 